\title{
Os Sujeitos da Educação de Jovens e Adultos da Escola Estadual de Ensino Médio 20 de Setembro
}

\author{
Los Sujetos de La Educación de Jóvenes y Adultos en la Escuela \\ Secundária 20 de Septiembre
}
The Subjects of Youth and Adult Education from the 20 de Setembro State Secondary School

Nádia Beatriz Machado Gomes ${ }^{1}$

Juliana Brandão Machado²

\begin{abstract}
Resumo
Este trabalho é parte de uma pesquisa junto ao Programa de Pós-Graduação em Educação da Unipampa e faz uma reflexão sobre a Educação de Jovens e Adultos (EJA) e as constantes mudanças, que atendendo aos interesses das classes dominantes, preocupados apenas ao desenvolvimento econômico da sociedade brasileira deixa de atender as necessidades da grande população. Reconhecer os sujeitos da EJA da Escola Estadual de Ensino Médio 20 de Setembro, localizada no município de Arroio Grande, na sua realidade, suas necessidades, no contexto da educação formal, buscando a superação da uniformidade, do aligeiramento e exclusão social é o objetivo deste trabalho. Busca-se nesse texto estabelecer um diálogo com autores do campo da Educação Popular e Educação de Jovens e Adultos, como Freire (1997), Beisiegel (1979); Haddad (2000); Arroyo (2011). A metodologia utilizou como coleta de dados um questionário aplicado aos alunos e documentos da escola. Destaca-se que essa análise envolve um questionário aplicado que se referem a realidade dos sujeitos na sua individualidade, na prática educativa, o uso das tecnologias digitais e como esses sujeitos se percebem no curso da modalidade EJA, estabelecendo uma relação com documentos da escola, com a concepção da educação emancipatória e o reconhecimento da cultura e do saber popular. Através desta proposta busca-se alternativas para melhorar a qualidade social desses jovens e adultos, afirmando-se enquanto sujeitos de uma ação transformadora, sabendo buscar seus conhecimentos, desenvolvendo valores humanos e diminuindo a exclusão social.
\end{abstract}

Palavras-Chave: Educação de Jovens e Adultos; Educação Emancipatória; Sujeitos

\section{Resumen}

Este trabajo es parte de una investigación junto al Programa de Posgrado en Educación de la Unipampa y reflexiona sobre la Educación de Jóvenes y Adultos (EJA) y los cambios constantes que, en vista de los intereses de la clase dominante, preocupados solo por desarrollo económico de la sociedad brasileña ya no satisface las necesidades de la gran población. Reconocer los sujetos de EJA en la Escuela Secundaria Estatal "20 de Septiembre", ubicada en el municipio de Arroyo Grande/ RS, en su realidad y sus necesidades, en el contexto de educación formal, buscando superar la uniformidad, el apurado y la exclusión social es el objetivo de este trabajo. Este texto busca establecer un diálogo con autores del campo de Educación Popular y Educación de Jóvenes y Adultos, como Freire (1997), Beisiegel (1979); Haddad (2000); Arroyo (2011). La metodología utilizada como recolección de datos es un cuestionario aplicado con estudiantes, los documentos escolar de la escuela. Es de destacar que este análisis involucra las preguntas del cuestionario aplicado y referido a la realidad de los sujetos en su individualidad, en la práctica educativa, el uso de tecnologías digitales y cómo estos sujetos se perciben en el estudio de la Modalidad EJA, estableciendo una relación con los documentos escolares y EJA

\footnotetext{
${ }^{1}$ Mestranda em Educação pela PPGEdu da Universidade Federal do Pampa, UNIPAMPA; Jaguarão, Rio Grande do Sul, Brasil; nadiagomesag@gmail.com

${ }^{2}$ Doutora em Educação e Professora do PPGEdu da Universidade Federal do Pampa, UNIPAMPA; Jaguarão, Rio Grande do Sul, Brasil; julianamachado@unipampa.edu.br
} 
desde la perspectiva de la educación emancipadora y el reconocimiento de la cultura y conocimiento popular. A través de esta propuesta buscamos alternativas para mejorar la calidad social de estos jóvenes y adultos para hacerlos más felices afirmando como sujetos de una acción transformadora, sabiendo buscar su conocimiento, desarrollando valores humanos y reduciendo la exclusión social.

Palabras-claves: Educación de Jóvenes y Adultos; Educación Emancipadora; Sujetos

\begin{abstract}
Abstract: This work is part of a research together with Post Graduation Program in Education from Unipampa and reflects on the Youth and Adult Education (EJA) and the constant changes that, meeting the interests of the ruling classes, only concerned with the economic development of the Brazilian society, no longer meets the needs of most of the population. Acknowledge the subjects of the EJA from the 20 de Setembro State Secondary School, located in the town of Arroio Grande/RS, in their reality, their needs, in the context of formal education, seeking the overcoming of uniformity, of acceleration and social exclusion is the purpose of the present work. It is aimed through this text to establish a dialogue with authors in the field of Popular Education and Youth and Adult Education, such as Freire (1997), Beisiegel (1979); Haddad (2000); Arroyo (2011). The methodology used as data collection a questionnaire applied to students and school documents. We highlight that this analysis refers to the reality of the subjects in their individuality, in the educational practice, the use of digital technologies and how these subjects see themselves in the EJA mode course, establishing a relationship with school documents, with the conception of emancipator education and the acknowledgement of culture and popular knowledge. Through this proposal we search for alternatives to improve the social quality of these youth and adults, consolidating as subjects of a transforming action, knowing how to search for their knowledge, developing human values and reducing social exclusion.
\end{abstract}

Keywords: Youth and Adult Education; Emancipatory Education; Subjects

\title{
1.Introdução
}

Este texto aborda a Educação de Jovens e Adultos (EJA) na perspectiva da Educação Popular, compreendendo seus sujeitos como construtores de sua história, em um processo de humanização que se constitui na integração dos sujeitos com as relações estabelecidas no contexto social e histórico.

A possibilidade dos seres humanos se construírem como seres em processo de humanização ou desumanização, se dá a partir do contexto real e histórico, vivido, experienciado, sofrendo as influências sociais, compreendendo o contexto herdado social e geneticamente, como dizia Freire (1997).

A história dos seres humanos é construída nas relações estabelecidas com a história que herdamos, com as pessoas e com o mundo aos quais fazemos parte. Nesta perspectiva, reconhecer os sujeitos da Educação de Jovens e Adultos (EJA) da Escola Estadual de Ensino Médio (E.E.E.M.) 20 de Setembro localizada no município de Arroio Grande/RS, na sua realidade experienciada, nas suas necessidades, no contexto da educação formal, buscando a superação do aligeiramento, da uniformidade e da exclusão social, passa a ser o objetivo desse trabalho.

Este artigo faz parte da pesquisa diagnóstica utilizada no Projeto de Mestrado do Programa de Pós-Graduação em Educação do Curso de Mestrado Profissional em Educação 
da Universidade Federal do Pampa e tem com título "Uma Proposta para a Educação de Jovens e Adultos baseada na Metodologia de Projetos de Aprendizagem".

Ao abordar esse tema, foi desenvolvido nesse texto uma reflexão sobre a EJA e Educação Popular na perspectiva de Freire (1997), Beisiegel (1979), Arroyo (2000) e Haddad (2011) e ainda uma breve análise a partir de uma coleta de dados realizada na documentação da escola e com os alunos da EJA matriculados no primeiro semestre do ano de 2019 da E.E.E.M. 20 de Setembro, localizada no município de Arroio Grande, Rio Grande do Sul.

Refletir sobre a EJA na perspectiva da Educação Popular é compreender o legado da EJA no seu aspecto histórico e no que diz respeito às ideias e conceitos de Freire quando faz referência à EJA e Educação Popular construídas a partir de elementos como "dialogicidade, humanidade, realidade contextualizada, construção coletiva do conhecimento, criticidade, autonomia e cultura como eixos importantes para o resgate da cidadania" (BRANDÃO, 2001, p. 09).

Freire contribuiu para a Educação Popular pulverizando no final década de 1950 e multiplicando as ideias na década de 1960 através dos Movimentos de Cultura Popular pautados pelo resgate da cidadania das pessoas, fundamentada na humanização, promovendo o desenvolvimento humano sobre o capital e perseguindo o direito a todos para o acesso, a permanência e a garantia de aprendizagem.

Beisiegel (1979, p.91) contribui dentro desta perspectiva quando se refere que a "educação popular adquire significado mais definido, na medida em que se orienta com vista a explicitar junto a segmentos mais populares da coletividade a sua condição de classe e as potencialidades inerentes a essa condição". A educação popular adquire o caráter de educação popular na base, a partir de uma realidade estruturada nas relações internas, no coração da sociedade, e não através de uma proposta política para atender imposições econômicas ou ideológicas de uma classe dominante na sociedade.

A EJA só terá valor social ao educando se na perspectiva da construção do conhecimento fizer a compreensão do mundo vivido, experienciado, tornando-se construtor de sua história. É preciso buscar um tempo mais humano para os jovens e adultos, reconfigurando a EJA e Arroyo (2011) afirma que o embate tem de ser estabelecido no campo do alargamento dessa estreita concepção de direitos sociais e humanos.

Segundo Haddad (2002), o Ensino Supletivo foi organizado para cumprir as funções de suplência, suprimento, aprendizagem e qualificação, tendo seus objetivos exigidos atingidos repondo a escolarização regular, formando mão-de-obra para atender ao mercado e atualizar conhecimentos. Entende-se que essa visão de ensino da EJA precisa ser reconfigurada. 
Dessa maneira, segundo Arroyo (2011, p.28) “A história mostra que o direito à educação somente é reconhecido na medida em que vão acontecendo avanços sociais e políticos na legitimação da totalidade de Direitos Humanos. A reconfiguração da EJA está atrelada a essa legitimação".

O artigo trará, na sequência, a metodologia utilizada na investigação, discussões teóricas sobre a EJA e a Educação Popular, análise dos dados coletados e as considerações finais sobre a necessidade do reconhecimento dos sujeitos da EJA como construtores de sua história.

\section{Metodologia}

O Projeto de Pesquisa desenvolvido no Programa de Pós-Graduação em Educação (PPGedu) da Universidade Federal do Pampa (Unipampa) faz parte da Pesquisa diagnóstica do Projeto de Intervenção de Mestrado que tem como título "Uma Proposta para a Educação de Jovens e Adultos baseada na Metodologia de Projetos de Aprendizagem".

O projeto de pesquisa está sendo desenvolvido na E.E.E.M. 20 de Setembro, localizada no município de Arroio Grande, sendo a única escola pública que oferece a EJA para alunos do Ensino Médio. Atende em torno 500 alunos, sendo que nesta modalidade são atendidos em torno de 250 alunos. A EJA tem sua participação na construção do Projeto Político Pedagógico (PPP), nas atividades propostas pela escola, assim como nas atividades específicas para a modalidade.

Para a realização dessa pesquisa diagnóstica foram estudados os documentos da escola como o PPP e os Planos de Estudos que referenciam o EJA na sua filosofia, o perfil de estudante, os objetivos da modalidade, a estrutura organizacional, a proposta metodológica. Ainda foram utilizados na coleta de dados as informações da Informatização da Secretaria da Escola (ISE) e um questionário aplicado aos alunos escolhidos para participar da pesquisa.

A escolha dos alunos foi estabelecida considerando o tempo de ingresso. Foram escolhidos os alunos que ingressariam no primeiro semestre do ano de 2019, portanto os alunos da totalidade 7 correspondendo ao primeiro ano do Ensino Médio. Dessa forma, permaneceriam mais tempo na escola possibilitando um tempo maior de contato para a realização da pesquisa, pois a conclusão do Ensino Médio na EJA ocorre em três semestres.

O reconhecimento dos sujeitos realizado pelo processo de informatização da escola assim como o questionário aplicado diretamente aos alunos, trouxe um conjunto de informações para atender as necessidades de compreender as principais características deste grupo: sexo, idade, local onde reside, as questões econômicas como atividade que realiza e programas sociais do governo que participa, os tempos escolares vivenciados e experienciados, o uso das tecnologias e "qual olhar" que vem a escola que hoje participam. 
As perguntas do questionário foram aplicadas aos alunos da Totalidade 7 no dia três de julho do ano de 2019, na disciplina de Sociologia e estavam presentes dezesseis alunos. O questionário foi organizado conforme o Quadro 1.

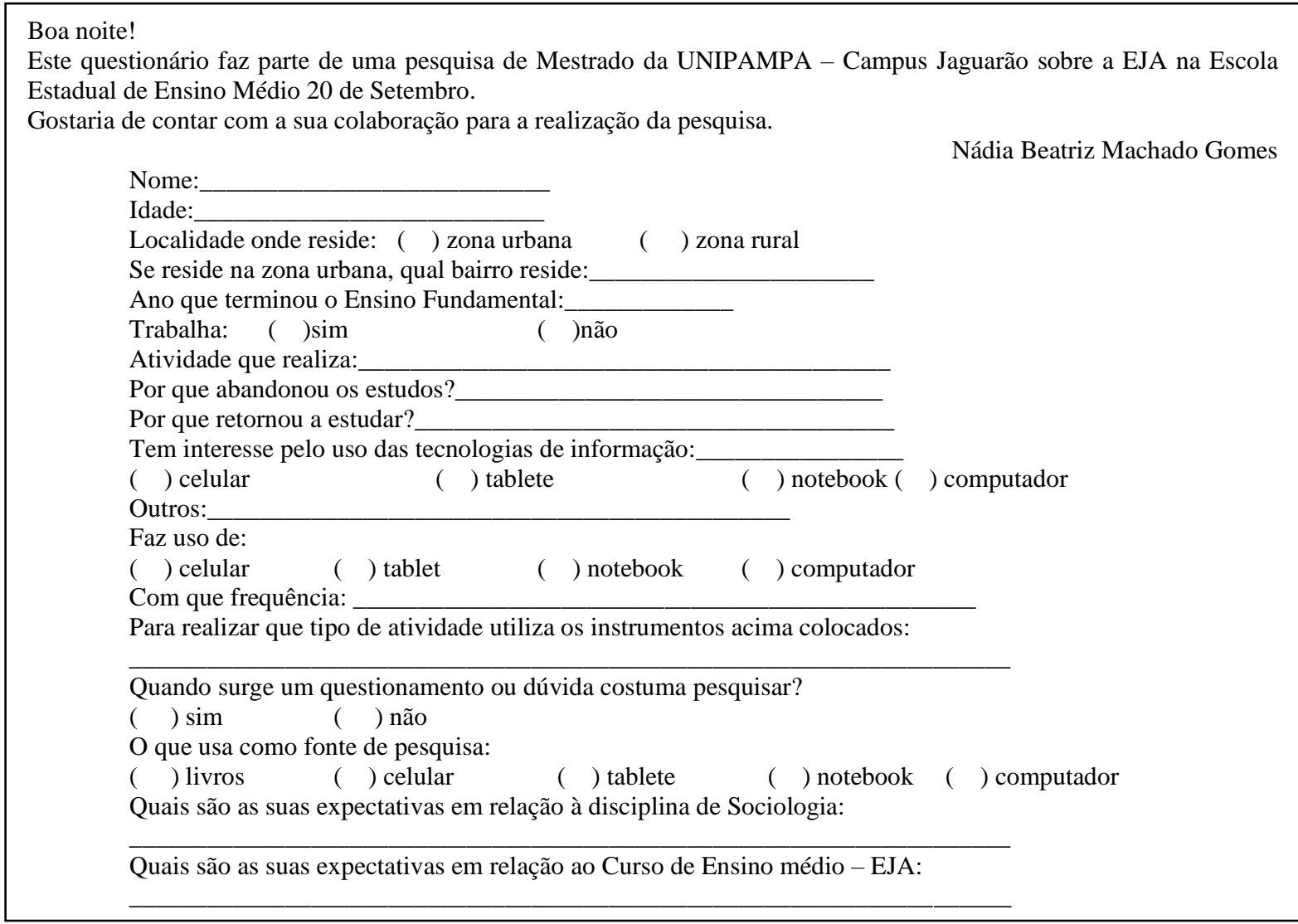

Quadro 1 - Questionário aplicado aos alunos

Fonte: Elaboração das pesquisadoras

A E.E.E.M. 20 de Setembro está inserida em um contexto social e econômico desumano pois na sociedade experienciada as diferenças sociais estão mais acentuadas, os direitos historicamente conquistados estão sendo desconsiderados e a aceitação das condições de vida impostas por uma sociedade capitalista está na consciência dos jovens e adultos.

Através do estudo do PPP e Plano de Estudos busca-se desenvolver uma educação reflexiva, humana, emancipatória e dialógica. Uma metodologia que parta do contexto real em que os alunos estão inseridos e proporcione a construção do conhecimento, buscando um aluno participativo, crítico, reflexivo e responsável.

Compreender os sujeitos da Educação de Jovens e Adultos na sua realidade experienciada, nas suas necessidades, no contexto da educação formal, buscando a superação do aligeiramento, da uniformidade e da exclusão social, é compreender que esta modalidade 
precisa ser reconhecida em sua estrutura que reflete uma sociedade desigual e referenciá-la no contexto da Educação Popular é a forma de buscar a superação da exclusão social.

\section{Fundamentação teórica}

Ao longo da história, o ser humano como parte do universo evolui, passando por transformações e transmitindo conhecimento às gerações futuras, para estas também as modificarem na busca de novas formas de ver o mundo. Ninguém nem nada ficam alheios a essa transformação. O mundo muda a cada dia e essas mudanças são resultantes das estratégias estabelecidas pelas classes dominantes (BEISIEGEL, 1979).

É preciso na escola ver o mundo por uma nova perspectiva, valorizando socialmente o educando na construção do seu conhecimento e da sua história, favorecendo o aparecimento de pessoas solidárias, desenvolvendo valores humanos, construindo espaços de forma sustentável e preocupando-se com a justiça social, diminuindo a exclusão e a diferença entre as classes sociais.

Freire (1997) resgata alguns saberes necessários à prática educativa que foram pulverizados e multiplicados nas décadas de 1950 e 1960 e nos permitem refletir sobre as questões relativas à Educação Popular. Dentre estes saberes, está a ideia de que é preciso acreditar na mudança social, que o nosso papel na sociedade não é só de quem constata os problemas sociais mas que intervém como sujeito, reconhecendo no futuro um problema e não um fato pronto e acabado, "é o saber da história como possibilidade e não como determinação. O mundo não é. O mundo está sendo" construindo por seres em processo de humanização (FREIRE, 1997, p. 85).

Beisiegel (1979) traz em seus textos que a questão da Educação Popular parte da base, do coração da sociedade, do conhecimento de mundo que os grupos populares fazem de suas realidades experienciadas e vividas e buscam através do diálogo e da troca a transformação social, ao contrário de uma prática autoritária que se vê como portadora de verdades absolutas que poderão salvar a sociedade, desconsiderando a compreensão do mundo realizada e compreendida pelas próprias classes populares.

Haddad (2000) afirma que a EJA vista sob o ponto de vista da suplência, tem seus objetivos associados a proposta econômica da sociedade, construindo uma educação de indefinição, de descompromisso público e de improvisação e esta proposta precisa ser superada por uma visão mais humana, trazendo um olhar atento aos jovens e adultos.

"É preciso configurar uma EJA como um campo específico do direito à educação e à formação de coletivos marcados por constantes sociais" (ARROYO, 2011, p.34). A imagem 
da EJA tem de ser reconstruída com olhares positivos, dentro da educação formal, com os direitos dos jovens e adultos sendo levados a sério e como política pública do Estado.

\section{Análise dos dados}

A partir dos dados coletados nos documentos da E.E.E.M. 20 de Setembro e do questionário aplicado aos alunos é possível compreender que o PPP e os Planos de Estudos refletem o que foi construído pela equipe administrativa, pedagógica e os professores que formam a EJA na Escola.

O PPP contempla

uma educação voltada para uma linha reflexiva, humanista, emancipatória e dialógica, que parta da realidade, do conhecimento, do interesse e da experiência, para construir e conquistar o saber, bem como socializá-lo, buscando sempre a coletividade (PPP, 2017, p.6).

O perfil de estudante que pretende formar é

um sujeito de sua própria formação, crítico, reflexivo, questionador, com uma autoestima elevada, que saiba resolver os problemas do cotidiano, participativo, responsável, consciente de suas ações, que cultive valores humanos e éticos. Um educando feliz (PPP, 2017, p.6).

A documentação da escola apresenta especificamente como objetivos da Educação de Jovens e Adultos:

Auxiliar o aluno a desenvolver uma consciência crítica a respeito do mundo que o cerca; Proporcionar aos educandos a reflexão sobre cidadania, favorecendo a formação de indivíduos críticos e conscientes de seus direitos e deveres, capazes de se tornarem agentes transformadores da realidade; Desenvolver o espírito democrático, de solidariedade, justiça e unidade social; Abrir novas perspectivas de estudos, tendo em vista a concepção de educação como processo permanente e dinâmico; Reordenar tempo e espaço escolar, respeitando o ritmo, os tempos de aprendizagem e as diferenças socioculturais promovendo a inclusão dos alunos com deficiência; Oportunizar situações para que os educandos possam construir conhecimentos através da formulação e do confronto de hipóteses, resolvendo problemas num processo ativo de interação sujeito/objeto/sujeito; Promover a inclusão social de jovens e adultos que não tiveram acesso à educação na idade própria, proporcionando condições para que essa parte da população construa sua cidadania e possa ter acesso a um currículo diversificado que provoque a ampliação dos saberes; Disponibilizar aos sujeitos jovens e adultos os bens socioculturais acumulados pela humanidade, sendo que tais conteúdos devem ser ressignificados, resgatando-se sua importância no processo ensino-aprendizagem, entendendo-se como saberes culturais (PLANO DE ESTUDOS, 2015, p.06-07).

Os Planos de Estudos (2015) organizam as turmas do Ensino Médio em totalidades, representadas pelas numerações 7,8 e 9 que correspondem ao $1^{\circ}$ ano, $2^{\circ}$ ano e $3^{\circ}$ terceiro ano do Ensino Médio. Preocupam-se não somente com a qualidade metodológica e técnica para aprendizagem efetiva, mas também com a formação e a autoformação das pessoas.

Os conteúdos das diferentes áreas de conhecimento (Linguagem, Ciências da Natureza, Ciências Humanas e Matemática) estão a serviço da construção de conceito, numa relação dialógica onde saberes são construídos a partir da ação-reflexão-ação.

No Plano de Estudos da EJA (2015, p.07) a metodologia de trabalho proposta é 
baseada em métodos ativos, dialógicos e críticos, onde todas as atividades e conteúdo são desenvolvidos a partir da consciência que se tem da realidade, evidenciando a construção do conhecimento pelo aluno, onde a aprendizagem é tida como processo, respondendo nos desafios constantes, do meio, em busca da transformação social, portanto, é realizada uma metodologia diversificada: aula contextualizada, trabalhos em grupo, pesquisas, filmes, dramatizações, aulas expositivas, jornais, palestras, campanhas educativas, debates, gincanas, jornadas pedagógicas, jogos, experiências científicas, trabalhos manuais e práticos, diálogos, reflexões, oficinas pedagógicas e outros.

A avaliação do desempenho dos alunos, parte integrante processo ensinoaprendizagem é

um momento de reflexão dos fatos e dos progressos de cada um, a fim de garantir que a aprendizagem se faça num processo contínuo de construção do conhecimento, assegurando a garantia de uma recepção qualificada e acompanhada pelos professores. (PLANO DE ESTUDOS, 2015, p.07).

A EJA da E.E.E.M. 20 de Setembro destaca no seu PPP e no Plano de Estudos uma educação reflexiva, emancipatória, dialógica e humanista, objetivando a formação de um sujeito crítico e questionador que saiba resolver problemas, cultive valores humanos, reflita sobre cidadania, justiça social, solidariedade e o espírito democrático, trazendo na sua documentação uma proposta de educação popular.

Conhecer os sujeitos da EJA da E.E.E.M. 20 de Setembro é uma necessidade para buscar uma proposta de educação popular dentro da EJA, conforme já mencionado, para buscar a compreensão de uma Educação Popular dentro da escola é necessário reconfigurar a EJA da uniformidade, do aligeiramento e da exclusão social, visto que esses sujeitos possuem uma diversidade nas suas especificidades, nas suas necessidades, nas suas relações estabelecidas com o mundo que os cercam e que precisam ser reconhecida no seu contexto.

Conforme destacado anteriormente, para a realização dessa pesquisa foi escolhida uma turma da Totalidade 7, com ingresso no primeiro semestre do ano letivo de 2019. Pesquisando nos dados oficiais da escola, através do programa de informatização, a turma apresentava trinta e um alunos matriculados, sendo quinze alunos do sexo masculino e dezesseis do sexo feminino, correspondendo uma faixa etária de 18 a 57 anos, sendo vinte e quatro alunos entre 18 a 28 anos, constatando através deste programa que os jovens estão buscando a escola através da EJA.

Dos trinta e um alunos, trinta alunos residem na zona urbana, em nove diferentes bairros da cidade e um aluno mora na zona rural, mostrando dessa forma que a escola como única a oferecer ensino médio modalidade EJA acolhe alunos de todos os bairros, considerando que não há transporte coletivo na cidade e o transporte rural para os alunos da EJA não é disponível pelo governo do estado, 
Foi constatado que dos trinta e um alunos, dez alunos recebiam benefícios entre bolsa família e "LOAS", trazendo a questão econômica, os alunos que buscam a EJA são desfavorecidos economicamente, ainda através de elementos que se apresentam no sistema ISE da escola, pode-se ter uma visão de que a EJA é representada pela diversidade, por jovens-adultos populares com trajetórias truncadas que se reconhecem sujeitos de direitos e necessitam de um olhar atento a sua própria história.

Analisando o questionário apresentado aos alunos, foi constatado que apenas dezesseis alunos responderam o questionário, sendo oito alunos do sexo feminino e oito do sexo masculino, conforme o Gráfico 1. De acordo com a matrícula inicial de trinta e um alunos, o número de alunos que continuam frequentando são vinte e três alunos, sete alunos deixaram de responder o questionário, desta forma observa-se que o número de alunos que abandonam a escola é expressivo.

Gráfico 1 - Distribuição dos sujeitos por sexo

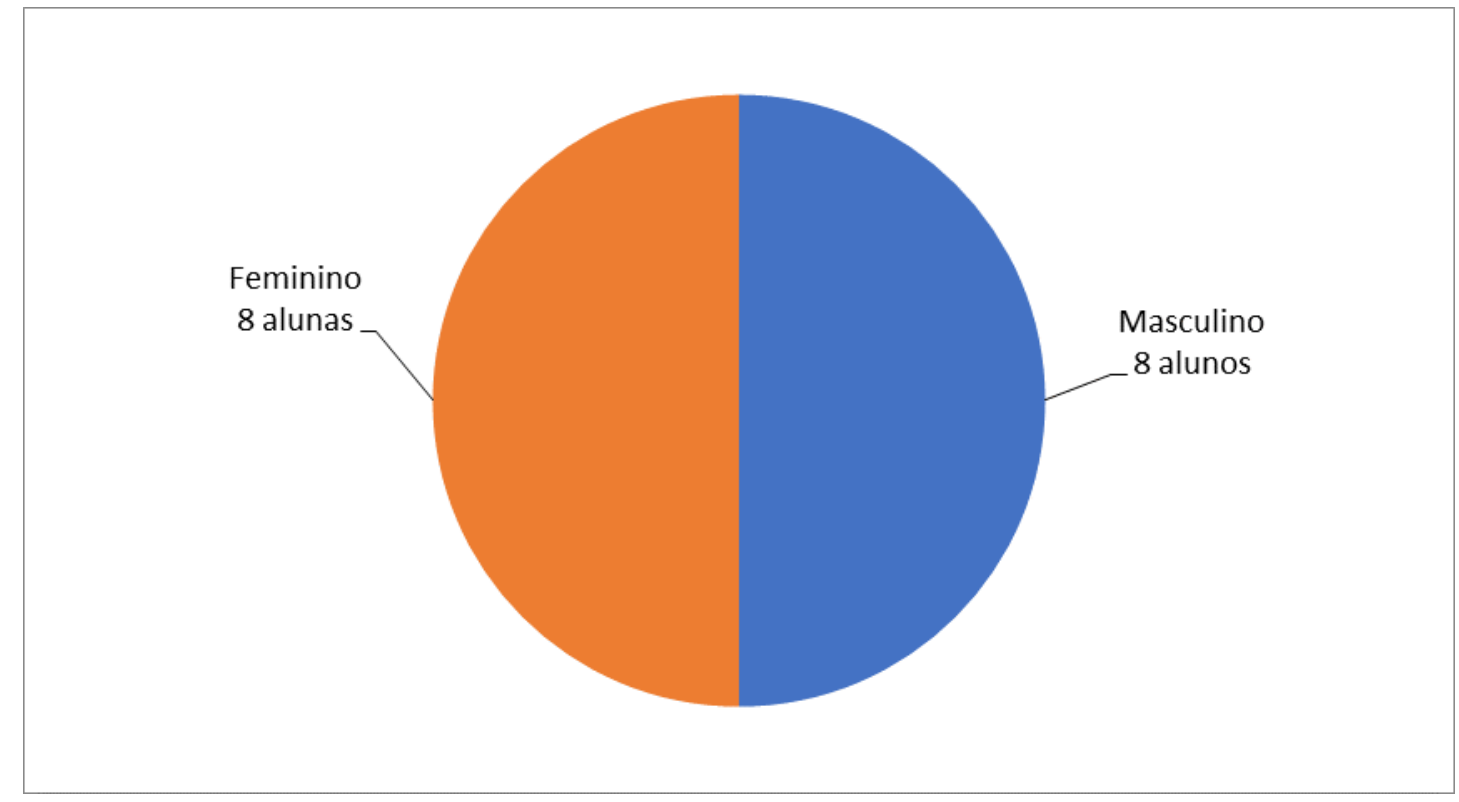

Fonte: Elaboração das pesquisadoras

No que se refere à faixa etária dos alunos que responderam o questionário, evidencia-se que os alunos da EJA são jovens em sua maioria, correspondendo que, do total de dezesseis que responderam o questionário, treze tinha entre dezoito e vinte e oito anos, conforme o Gráfico 2. 


\section{Gráfico 2 -}

Distribuição dos sujeitos por faixa etária

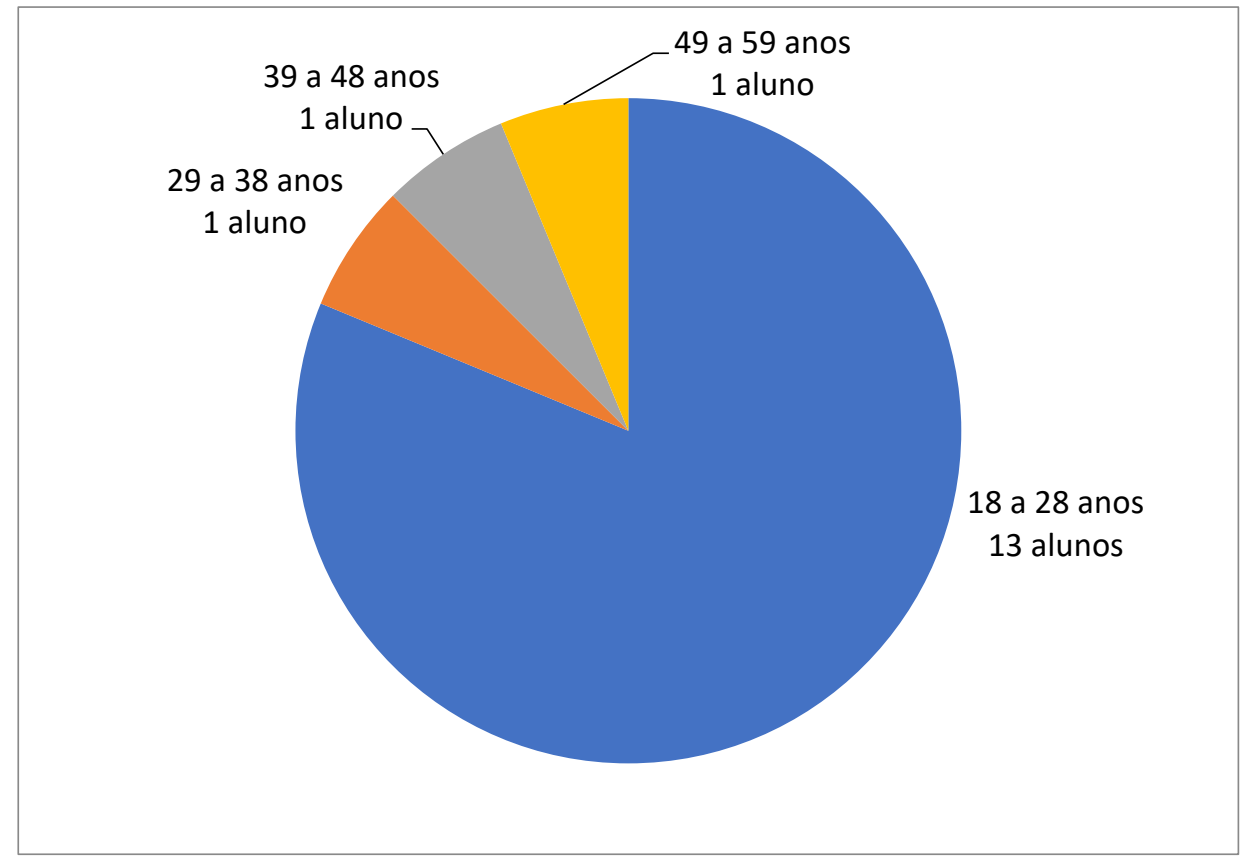

Fonte: Elaboração das pesquisadoras

Os alunos também evidenciaram dados referentes aos espaços que ocupam no que se refere à moradia. Dos dezesseis alunos respondentes, um mora na zona rural e utiliza o transporte escolar "de carona" para vir para à escola, pois os alunos da EJA não têm direito ao transporte escolar público. Os demais quinze alunos questionados residem em diferentes bairros da cidade, em espaços mais periféricos, conforme mostra o Gráfico 3.

Gráfico 3 - Bairros da zona urbana em que residem

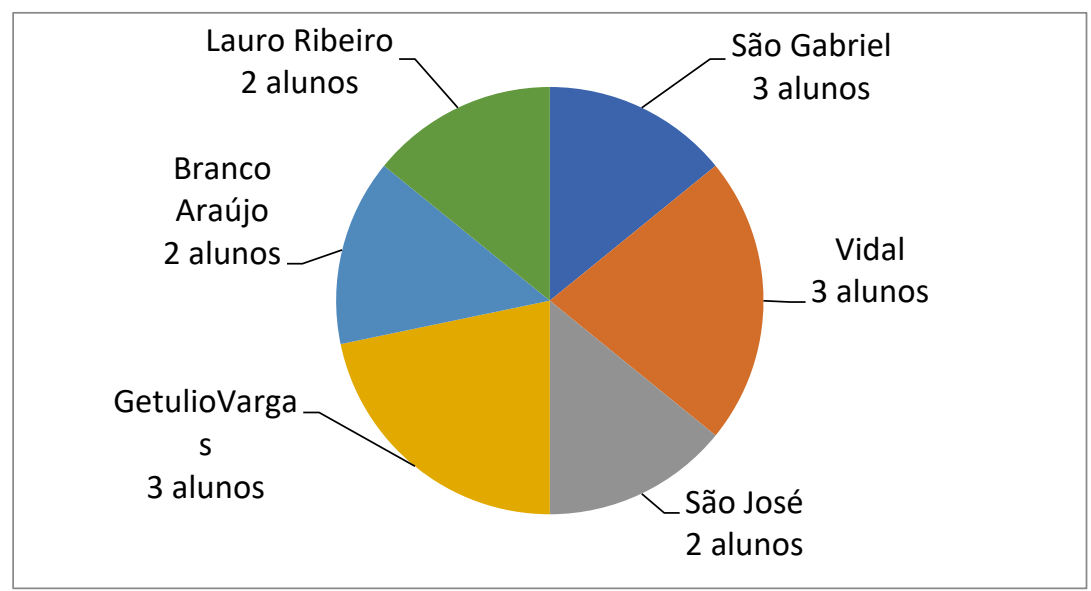

Fonte: Elaboração das pesquisadoras. 
Foi constatado através deste instrumento que dez dos dezesseis alunos possuem ocupações como cuidadores, construção civil, serviços gerais ou funcionários públicos. Outros possuem bolsa família ou vivem do "LOAS", programas sociais do governo destinados aos cidadãos de menor renda.

Os alunos mostram através da pesquisa que abandonaram os estudos para trabalhar, nove dos dezesseis alunos disseram que não abandonaram os estudos, fizeram matrículas nas escolas, mostrando dessa forma trajetórias escolares truncadas, o que os levou a chegar aos dezoito anos sem concluir o primeiro ano do Ensino Médio.

Arroyo (2011) afirma que as trajetórias escolares desses jovens adultos, assim como a história da educação de jovens e adultos, precisam de um olhar atento. A escola não supera as carências que a sociedade impõe, mas precisa conhecer os sujeitos de direito, assim como é tarefa da escola discutir a trajetória dos sujeitos inseridos na EJA e uma história comprometida com as classes populares compartilhando saberes e resgatando-se humano.

Os alunos indicaram o uso das tecnologias digitais, em especial o celular, para realizar pesquisas, usar as redes socias e comunicar-se, o que possibilita uma intensa fonte de informações e de conhecimentos que a escola tem a função desveladora, crítica e questionadora, buscando um diálogo entre as informações que recebem, o que Freire chama de tomada consciência.

Os alunos ainda, ao avaliar a modalidade EJA, destacam buscar nos espaços escolares um trabalho melhor, além de valorizar as relações interpessoais estabelecidas na escola, relações entre professores e alunos e entre os próprios alunos. Valorizar as relações afetivas estabelecidas na escola é trazer Freire em seu poema que diz: "Escola é... onde se faz amigos, não se trata só de prédios, salas, quadro, programas, horários, conceitos ...Escola é sobretudo gente, gente que trabalha, que estuda, que se alegra, se conhece, se estima...".

No que se refere à EJA, conforme o Gráfico 4, os alunos mencionaram que nada precisa melhorar no curso, apenas um aluno coloca que é preciso falar mais sobre a história do Rio Grande do Sul e outro aluno a necessidade de melhorar o transporte para os alunos que moram na zona rural e querem estudar, demonstrando dessa forma uma visão ingênua, individual, não crítica, simples, sem qualquer análise do curso para atender as necessidades reais. 
RELACult - Revista Latino-Americana de Estudos em Cultura e Sociedade

Gráfico 4 - Aspectos a serem melhorados no curso - EJA

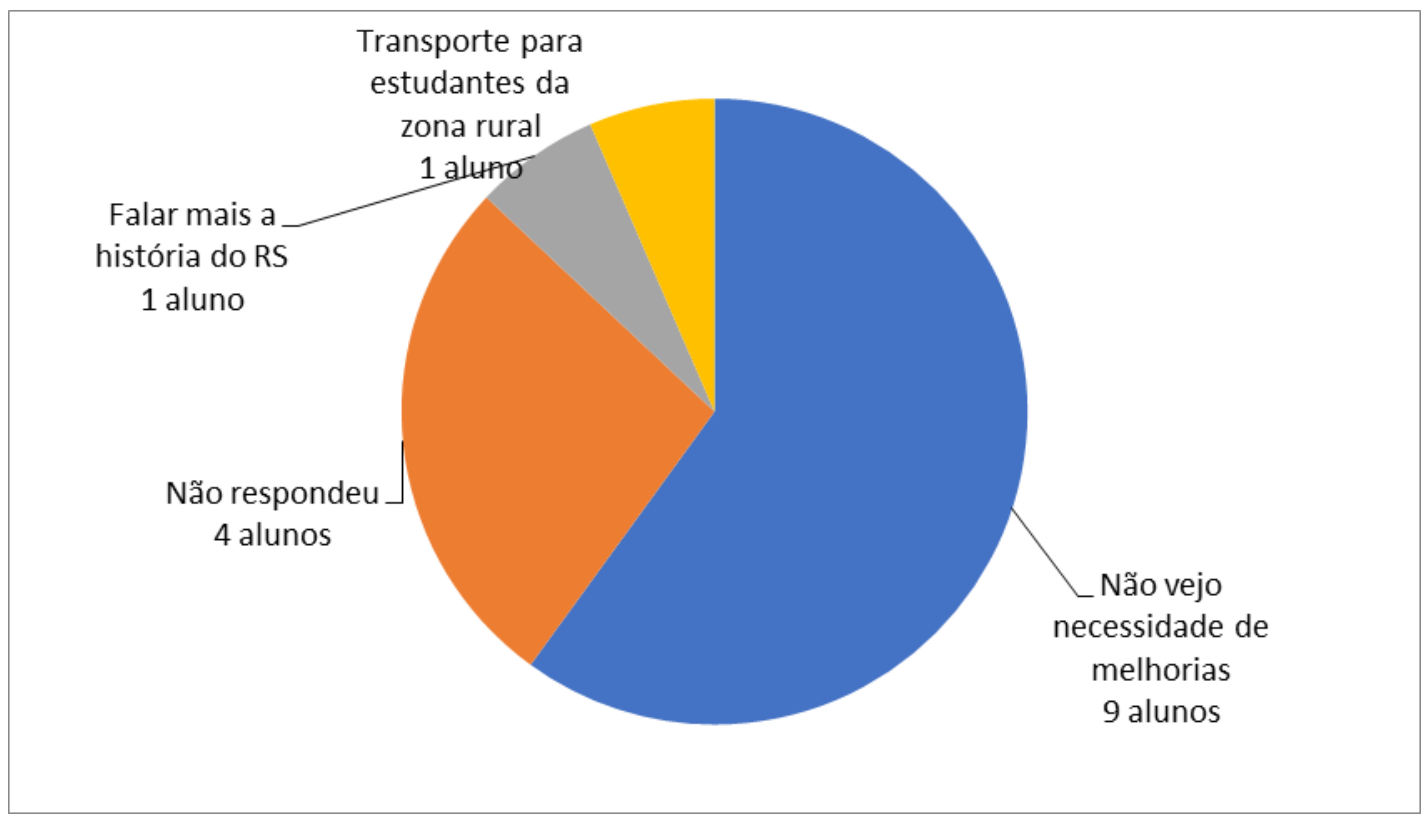

Fonte: Elaboração das pesquisadoras.

Superar a ingenuidade, buscar uma visão mais crítica da realidade experienciada e refletir sobre o desvelamento dos fatos, é a retirada do véu que envolve as tensões e os conflitos da realidade, é a tomada de consciência que está intimamente ligado à tomada de consciência que produz desmitologização.

\begin{abstract}
É tirar o véu que encobre a realidade, sem a pretensão de acesso à verdade absoluta e com a humildade da consciência que se sabe falível, pois a onisciência não é uma possibilidade humana. O trabalho humanizante não pode ser outro senão o de ampliar o diálogo. Nesse sentido, o olhar da conscientização é o mais crítico possível das facetas do mundo da vida, procurando contribuir para o desvelamento da perversidade do processo de alienação que transforma o ser humano, potencialmente sujeito da sua história, em coisa, mercadoria com valor de troca, cada vez mais aviltado pelo discurso naturalizador das elites dominantes, que continua mantendo a ilusão de uma realidade imutável, inexorável, que não tenha a autoria humana e não possa ser transformada (VIZEU; ROCHA, 2011).
\end{abstract}

Acreditar nos sujeitos da EJA em suas potencialidades e capacidades é ver os sujeitos em todas assuas dimensões, é desconstruir a dominação que historicamente serviu para balizar as relações autoritárias e construir com os sujeitos a superação das contradições em que se encontram, tomando consciência da sociedade, permitindo um nível mais profundo de criticidade para obter melhores escolhas para encarar o mundo e seus problemas.

\title{
5.Considerações Finais
}

Considerando que o objetivo desse texto é reconhecer os sujeitos da EJA da E.E.E.M. 20 de Setembro localizada no município de Arroio Grande/RS, na sua realidade experienciada; nas suas necessidades; no contexto da educação formal; buscando a superação 
do aligeiramento, da uniformidade e da exclusão social, abordar a EJA na perspectiva da educação popular é a principal tarefa desse artigo.

Diante dos dados recolhidos no ISE e a aplicação dos questionários, é possível constatar que a evasão faz parte da EJA. A pesquisa mostrou no primeiro semestre de 2019 um percentual elevado de evasão, o que revela um tema a ser pesquisado futuramente. Através dos dados coletados no questionário, observamos que os sujeitos da EJA são jovens e possuem a maioria entre 18 a 28 anos, os jovens-adultos do sexo feminino estão em igual número aos do sexo masculino, então homens e mulheres buscam a continuidade dos estudos na EJA. Estes dados são constatados antes e depois da evasão, ou seja, o número de matriculados do sexo feminino e masculino no início do ano letivo era o mesmo.

Os sujeitos da pesquisa em sua maioria moram na zona urbana, em bairros distantes da escola, trazendo aos alunos que realizam atividades de ocupação durante o dia, dificuldades para chegar a escola à noite, pois não há transporte coletivo. Ainda, o único aluno que mora na zona rural só está na escola por que usa transporte próprio ou vai "de carona" com o transporte dos alunos do Ensino Médio do ensino regular, pois o governo não disponibiliza transporte para alunos da EJA que moram na zona rural.

Os jovens-adultos pesquisados realizam atividades de ocupação em sua maioria informais, com baixa remuneração, outros possuem como renda o "LOAS" ou Bolsa Família, pois não se encontram em condições de trabalhar. Ainda, chegaram ao EJA com históricos de reprovações e abandono escolar, lacunas que a sociedade os condena, "carregam trajetórias fragmentadas que se contrapõem a linearidade do pensar e fazer pedagógico" (ARROYO, 2011, p.36). Nesse sentido, entendemos que a EJA tem a função de refletir as formas truncadas e fragmentadas de jovens e adultos que cotidianamente a escola se defronta.

As formas truncadas que precisam ser refletidas estão na idade de jovens alunos que buscam a EJA, no abandono à escola, nas reprovações que os sujeitos passam nas trajetórias escolares. Arroyo (2011, p.46) afirma que "a EJA não foi inventada para fugir do sistema público, mas porque neste não cabiam as trajetórias humanas dos jovens e adultos populares".

A EJA construiu uma história comprometida com as classes populares e considera os saberes e conhecimentos que os sujeitos acumularam nas suas trajetórias de vida um ponto de partida para o diálogo entre os saberes populares, saberes escolares e saberes sociais. Estabelecer este diálogo é a garantia do direito ao conhecimento, à ciência e à tecnologia.

Nessa perspectiva, cabe salientar a importância da EJA na superação do aligeiramento, uniformidade e exclusão social e necessita reconhecer os sujeitos da EJA na sua realidade 
experienciada; nas suas necessidades; no contexto da educação formal abordando a perspectiva da educação popular.

Proporcionar a reflexão em torno das práticas pedagógicas e das políticas públicas em torno da EJA, desencadeando um diálogo com referenciais da perspectiva da Educação Popular que despertam a dúvida, questionam certezas e estimulam a ousadia, possibilitarão a construção de políticas públicas garantindo a todos o direito à educação nas especificidades das trajetórias vividas pelos sujeitos que formam a EJA.

\section{Referências}

ARROYO, M. G. Educação de jovens e adultos: um campo de direitos e de responsabilidade pública. In. SOARES, L.; GIOVANETI, M. A. G. C.; GOMES, N.L.; Diálogos na educação de Jovens e Adultos. Belo Horizonte, 2011.

BEISEGIEL, C.R. Cultura do povo e educação popular. Revista Faculdade de Educação. São Paulo,5 (1/2):77-92. $1979 . \quad$ Disponível em: http://www.revistas.usp.br/rfe/article/vrew/33245/35987. Acessado em 12. abr. 2109.

BRANDÃO, C. R. (Org.). De angicos a ausentes: 40 anos de educação popular. Porto Alegre: Corag, 2001.

FREIRE, P. Pedagogia da Autonomia: saberes necessários a prática educativa. São Paulo, Paz e Terra. 1997.

FREIRE, P. A Escola é. Disponível em: www.paulofreire.org. Acesso em: 26 dez.2019

HADDAD, S. (Org.) Educação de Jovens e adultos no Brasil (1986-1998).Brasília: MEC/Inep.Comped.Brasília, 2002. Disponível em: http://www.uems.br/propp/conteudopos/ceja/Educ_Jovens_Adultos_EstConhecimento.pdf

PLANO DE ESTUDOS DA EDUCAÇÃO DE JOVENS E ADULTOS. Escola Estadual de Ensino Médio 20 de Setembro. Arroio Grande. 2015.

PROJETO POLÍTICO PEDAGÓGICO. Escola Estadual de Ensino Médio 20 de Setembro. Arroio Grande. 2017.

VIZEU, A.; ROCHA, H. $O$ desvelamento de Paulo Freire. Disponível: http://observatoriodaimprensa/diretorio-academico/o-desvelamento-de-paulo-freire/. Acesso em: 04 dez.2019. 